\title{
Comparison of Rainy Season Onset, Cessation and Duration for Ghana from RegCM4 and GMet Datasets
}

\author{
Caleb Mensah ${ }^{1}$, Leonard K. Amekudzi ${ }^{*}$, Nana Ama B. Klutse ${ }^{3}$, Jeffrey N. A. Aryee², \\ Kofi Asare ${ }^{1}$ \\ ${ }^{1}$ Ghana Meteorological Agency, Accra, Ghana \\ ${ }^{2}$ Meteorology and Climate Science Unit, Department of Physics, Kwame Nkrumah University of Science and \\ Technology, Kumasi, Ghana \\ ${ }^{3}$ Remote Sensing, GIS and Climate Center Ghana Space Science and Technology Institute, Accra, Ghana \\ Email: "leonard.amekudzi@gmail.com
}

Received 11 March 2016; accepted 22 April 2016; published 25 April 2016

Copyright (C) 2016 by authors and Scientific Research Publishing Inc.

This work is licensed under the Creative Commons Attribution International License (CC BY). http://creativecommons.org/licenses/by/4.0/

(c) $\underset{\mathrm{EY}}{\mathrm{i}}$ Open Access

\section{Abstract}

The socio-economic sector of West African countries is rain-fed agriculture driven. Information regarding the onset, cessation and duration of the rainy season is thus, very essential. In this paper, a comparison of the onset, cessation and duration of the rainy season has been carried out using simulated rainfall data from the fourth generation Regional Climate Model (RegCM4) and rain gauge measurements from Ghana Meteorological Agency (GMet), covering a period of 1998 to 2012. Similar onset and cessation dates were seen in both the simulated and guage rainfall measurements for the various agro-ecological zones, resulting in similar duration of the rainy season. The average duration of the rainy season were less than 200 days for the savannah and coastal zones whereas the duration of the rainy season were beyond 200 days for the forest and transition zones. The bias of these comparisons was less than $\mathbf{3 0}$ days and the root mean square error (RMSE) values were less than 15 days for all stations, except Saltpond. The Pearson's correlation (r) typically ranged between 0.4 and 0.8 . However, negative correlations were observed for Tamale in the savannah zone, and the entire coastal zone. These findings are indications that RegCM4 has the potential to clearly simulate the movement of the rain belt, and thus, could fairly determine the onset, cessation and duration of the rainy season. The findings have significant contributions to effective water resource management and food security in Ghana, as the thriving of these sectors depend on the dynamics of the rainfall seasons.

\footnotetext{
"Corresponding author.
} 


\section{Keywords}

\section{Onset, Cessation, Duration of Rainy Season, GMet, Ghana, RegCM4}

\section{Introduction}

Rainfall is a major factor that determines crop choice and yield, as well as, success of other socio-economic activities in West Africa. The variability of rainfall onset, cessation and duration affect planting (sowing) dates, crop growth, yield and food production [1] [2]. Moreover, projected rise in population by 2050, is a concern for food stability and natural resource base conservation, and thus, there is the need to investigate the variability of the onset, duration and cessation of the rainfall season over the West African Climate [3]. In Ghana, as in other West African countries, the knowledge on past and present onset, cessation and duration of the rainy season will inform prediction and planning of appropriate interventions towards ensuring yield stability.

In an earlier paper, Amekudzi et al. (2015) [2] extensively studied the variability of rainfall onset, cessation and growing season over the country using the rainfall amount and rainy days approach. Similarly, researchers like Olaniran (1983, 1984) [4] [5], Adejuwon et al. (1990) [6] and Odekunle (2006) [7] determined the onset and cessation of the rainfall season from only gauge data. Le Barbe et al. (2002) [8], also studied the onset of rains over West Africa with annual oscillations of the weather zones characterizing the West African climate. Cocheme et al. (1967) [9] and Benoit (1977) [10] determined the onset and cessation of the growing season from the relationship between rainfall and evapotranspiration. Alternatively, Omotosho (2002) [11] used the Theta-E technique, which depends on the equivalent potential temperature.

Although numerous onset and cessation studies have been carried out, very few utilized an integrated network of gauge and regional climate models (RCMs). RCMs, in rainfall analysis over West Africa, have the potential to enhance prediction of onset, cessation and duration of the rainy season. For example, RegCM4 allows for the capturing of detailed climate variations over shorter spatial scales [12]. As a result, it may be able to simulate the movement of the rain belt, as well as, the position and strength of the Inter Tropical Discontinuity (ITD), with other associated changes which affect the rainy season. An added advantage is the ability of RegCM4 to capture complex terrain and land-use cover, allowing for the integration of regional topographic and vegetation effect within the model simulation [12]. This makes RegCM4 a useful model for simulating rainfall events over West Africa.

The goal of this paper is to inter-compare the onset, cessation and duration of the rainy season for Ghana using RegCM4 simulation and gauge data. This will provide the opportunity to test the potential of RegCM4 in simulating the rainfall events over West Africa. The paper is structured as follows: datasets and the study site are described in Section 2 with methodology given in Section 3. The results are discussed in Section 4 and finally, the conclusion of this study is presented in Section 5.

\section{Study Area and Data Source}

\subsection{Description of Study Area and Rainfall Characteristics}

The study area, Ghana, is divided into four agro-ecological zones (savannah, transition, forest, coast) based on GMet's classification [1]-[3]. Rainfall over the country is linked with the annual forth and back passage of the ITD. The savannah zone is characterized by a unimodal rainfall pattern, with August being the peak rainfall month in the zone. Over the years, the agricultural potential in this zone has been significantly affected by high rainfall variability and poor soils [1] [13]. The transition zone lies between the savannah and the forest zones. Rainfall within the transition is bimodal, with September to October being the peak rainfall months. The forest zone covers the central part and the south-western coast of the country. Rainfall pattern for the forest zone is also bimodal, with June as the peak rainfall month. A minor peak occurs in October, within the minor season. The major and minor rainfall seasons are separated by the so-called Little Dry Season, occurring in August [8]. This dry spell could last for 3 to 6 weeks within a year. The coastal zone covers the low grassland coastal strip of south-eastern Ghana, where rainfall pattern is bimodal and June is the peak rainfall month. The onset, cessation and duration of the rainy season within the four agro-ecological zones follow the migration of the ITD. None- 
theless, local topographical features such as orographic effect, foehn winds and nature of the coastline could also contribute to the rainfall system [2] [8] [14]. With respect to agriculture, the forest and transition zones are the most productive zones of the country, and are often referred to as the cash crop and food basket of the country [15].

\subsection{Data Source}

Daily rainfall data from twenty (20) synoptic stations over Ghana (see Figure 1), from 1998 to 2012 were sampled from GMet. Like other meteorological agencies under the World Meteorological Organisation (WMO), GMet employs WMO's standards in its rainfall measurements. However, there may exist minor inconsistencies in the rainfall measurements, such as evaporation and wetting losses and wind induced errors. However, the rain gauges were wind shielded, hence wind induced, evaporation and wetting losses were negligible [2].

Furthermore, RegCM4 was used to simulate rainfall for the 20 respective stations. RegCM4 is a regional climate model of the Earth Science Department of the Abdus-Salam International Centre for Theoretical Physics (ICTP) [12]. The model is hydrostatic and with discrete finite-difference and vertical sigma coordinate. The RegCM4 was developed for simulating long-term regional climate and has been used in various regional model intercomparison projects [12] [16] [17] and paleo- to future climate projections. The model simulations were ran at a spatial resolution of $15 \mathrm{~km}$ and with 18 vertical levels over Ghana. The simulated rainfall data were further downscaled to the 20 respective synoptic stations at a daily temporal resolution.

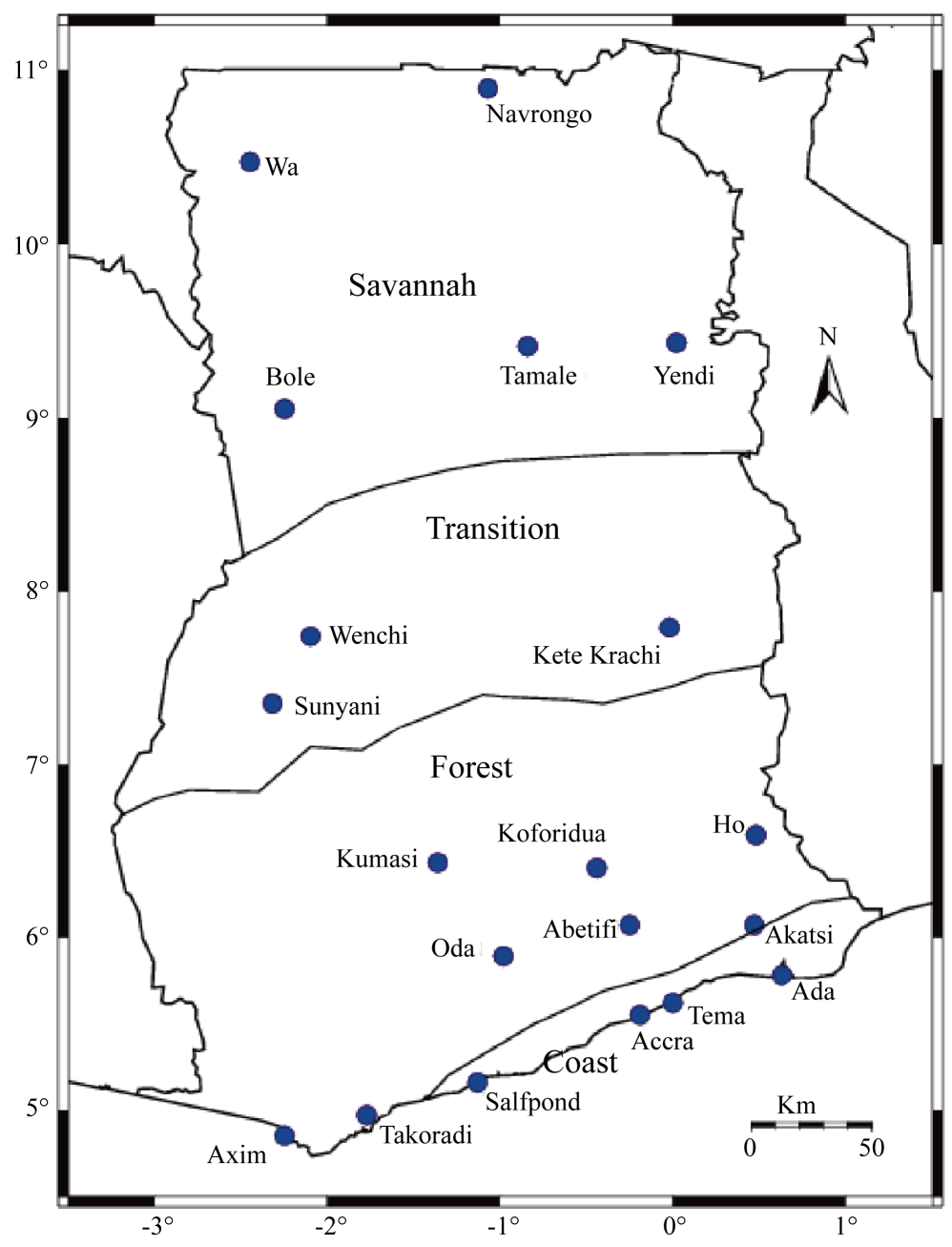

Figure 1. The map of Ghana showing all the GMet Synoptic Stations (blue dots) used for this study, adopted from Amekudzi et al. (2015) [2]. 


\section{Methodology}

\subsection{Determination of Onset, Cessation and Duration of Rainy Season}

The fuzzy-logic approach was used in determining the onset, cessation and duration of the rainy season. The onset date for the rains was defined as the first day of a 5-day period with a total of at least $20 \mathrm{~mm}$ of rainfall recorded. Also, the starting day and at least two other days in this 5-day period must be wet (at least $1 \mathrm{~mm}$ of rainfall recorded), with no dry spell of seven or more consecutive days occurring in the subsequent 30 days [18]. Onset dates were calculated from Equation (1), given by

$$
\mathrm{OD}=D \frac{(20-F)}{R},
$$

where OD is the onset date and $D$ is the total number of days in first month with effective rain (MER: the accumulated rainfall totals equal or exceeds $20 \mathrm{~mm}) . F(\mathrm{~mm})$ is the accumulated rainfall total of earlier months and $\mathrm{R}$ is the accumulated rainfall within the MER.

Rainfall cessation dates were also calculated using Equation (2), given by

$$
\mathrm{CD}=b+275 \text {, }
$$

where $\mathrm{CD}$ is the cessation date and is defined from the equation as any day from 1st October after which there are more than 7 consecutive days of rainfall with amounts below $50 \%$ of the soil water requirement and b denotes the number of days in which there is maximum build-up of pre-season moisture. The duration of the rainy season is the difference between the cessation and onset, which is expressed as (CD - OD + 1).

\subsection{Validation}

Three statistical measures, described in [2] [19] and [20] were used to assess the agreement between the gauge and RegCM4 onsets and cessation. The bias, Pearson's correlation $\left(r_{x y}\right)$ coefficient and root mean square error (RMSE) are given in Equations (3), (4) and (5).

$$
\begin{gathered}
\text { Bias }=\frac{1}{N} \sum_{i=1}^{N}\left|x_{i}-y_{i}\right| \\
r_{x y}=\frac{\sum_{i=1}^{N}\left(x_{i}-\mu_{x}\right)\left(y_{i}-\mu_{y}\right)}{(N-1) S_{x} S_{y}} \\
\text { RMSE }=\frac{1}{N} \sqrt{\sum_{i=1}^{N}\left(x_{i}-y_{i}\right)^{2}}
\end{gathered}
$$

where $x$ is the gauge data, $y$ is the RegCM4 model data, $\mu_{x}$ and $\mu_{y}$ are the arithmetic mean of $x$ and $y$ respectively and $S_{x}$ and $S_{y}$ are the standard deviation of $x$ and $y$ respectively.

\section{Results}

\subsection{Rainfall Onset}

The onset of rains was determined from both the gauge and the RegCM4 model rainfall data over the 20 synoptic stations. For the stations in the savannah zone, the mean rainfall onset dates were determined to be the third dekad of April and the first dekad of May for the gauge and model respectively (see Table 1). In the transition zone, the mean rainfall onset date was identified in the first and second dekad of April for the gauge and model respectively. The mean rainfall onset for the forest zone was found to be in the third dekad of March for both gauge and model. Onsets for the forest zone were much earlier than the transition zone and this is possibly due to the gradual migration of the ITD northwards. Moreover, the similar onset dates identified for both gauge and the model is an indication of good performance of the model in estimating the onset of the rainy season in the forest zone. The model however underperformed in its estimation of the onset of rains over the coastal zone, with mean rainfall onset dates located in the first and third dekad of April for the gauge and model respectively. 
Table 1. Distribution of mean rainfall onset dates for all stations.

\begin{tabular}{|c|c|c|}
\hline Station & GMet Mean OD & RegCM4 Mean OD \\
\hline Abetifi & $91 \pm 10$ & $93 \pm 10$ \\
\hline Accra & $123 \pm 07$ & $112 \pm 05$ \\
\hline Ada & $116 \pm 07$ & $110 \pm 05$ \\
\hline Akatsi & $109 \pm 07$ & $76 \pm 07$ \\
\hline Akim Oda & $74 \pm 07$ & $115 \pm 05$ \\
\hline Axim & $87 \pm 10$ & $85 \pm 05$ \\
\hline Bole & $100 \pm 05$ & $110 \pm 05$ \\
\hline Ho & $70 \pm 07$ & $76 \pm 07$ \\
\hline Kete Krachie & $121 \pm 07$ & $105 \pm 05$ \\
\hline Koforidua & $94 \pm 05$ & $93 \pm 05$ \\
\hline Kumasi & $80 \pm 07$ & $83 \pm 05$ \\
\hline Navrongo & $132 \pm 05$ & $120 \pm 05$ \\
\hline Saltpond & $112 \pm 07$ & $61 \pm 05$ \\
\hline Sunyani & $83 \pm 05$ & $115 \pm 05$ \\
\hline Takoradi & $104 \pm 10$ & $86 \pm 05$ \\
\hline Tamale & $127 \pm 07$ & $128 \pm 05$ \\
\hline Tema & $120 \pm 07$ & $112 \pm 05$ \\
\hline Wa & $111 \pm 05$ & $130 \pm 05$ \\
\hline Wenchi & $90 \pm 07$ & $88 \pm 05$ \\
\hline Yendi & $92 \pm 05$ & $123 \pm 05$ \\
\hline
\end{tabular}

On the whole, earliest onsets were observed at Akim-Oda and Ho in the forest zone whereas the model identifies the earliest onsets at Saltpond in the coast and Akuse and Ho in the forest zone (see Table 1). The latest onsets, as identified by the gauge, were at Navrongo and Tamale in the North, Kete-Krachi, in the transition, and Accra and Tema, in the coast (see Figure 2(a)). The RegCM4 model, however, identified the savannah stations to be the receipients of the late onset of rains (see Figure 2(b)), which is a confirmation of an earlier study by [2].

\subsection{Rainfall Cessation}

The mean rainfall cessation dates, for the savannah zone, were determined to be the second dekad of October for both the gauge and RegCM4 model. The model rightly captured the cessation of rainfall in the savannah zone. In the forest zone, the mean cessation was found to be in the second dekad of November for the gauge and the first dekad of November for the RegCM4 model. The cessation dates are similar and again this is an indication of better performance of the model in estimating the cessation of rains in the forest zone. Furthermore, the mean rainfall cessation dates were also identified to be within the third dekad of November for gauge and the second dekad of November for the model. Finally, the first dekad of November and the third dekad of October were observed as the mean cessation dates for the gauge and model respectively, in the coastal zone. The model again underperformed in estimating the cessation date of the rainy season for the coastal zone. Rainfall cessation, over the entire country, was observed after September. The latest cessation, as observed from the gauge, was at Wenchi and Kete Krachi in the transition zone. The RegCM4 model also identified Wenchi as the station with the latest cessation (see Figure 2(c) and Figure 2(d)). 
(a) GMet Onset

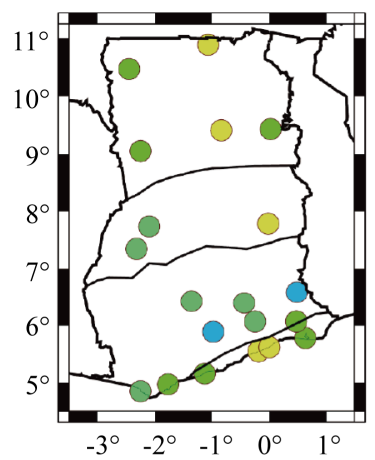

(c) GMet Cessation

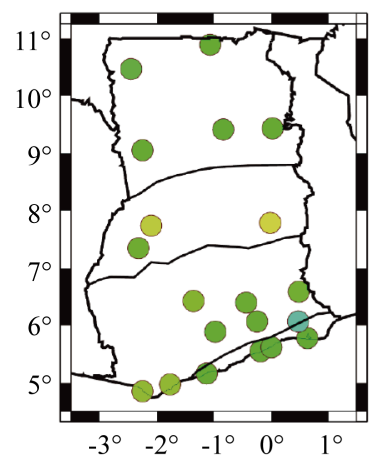

(e) GMet Length

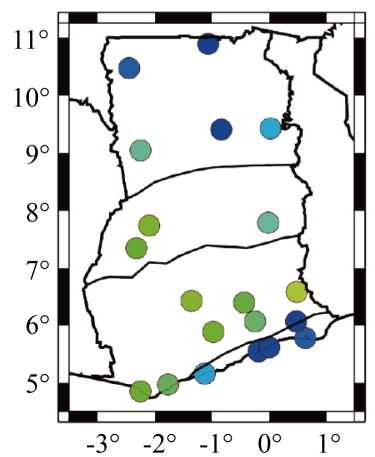

(b) RegCM Onset

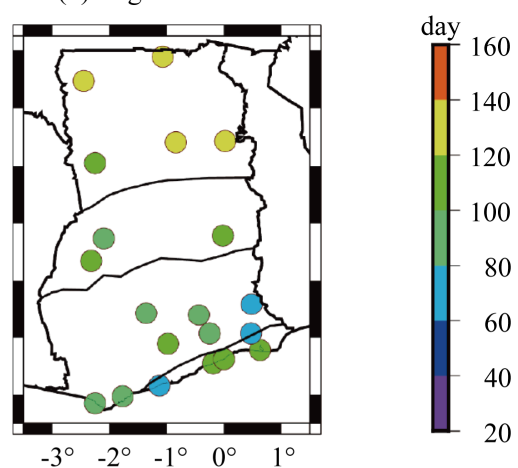

(d) RegCM Cessation

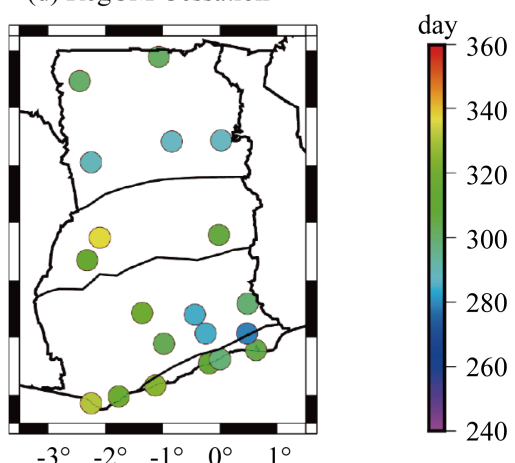

(f) RegCM Length

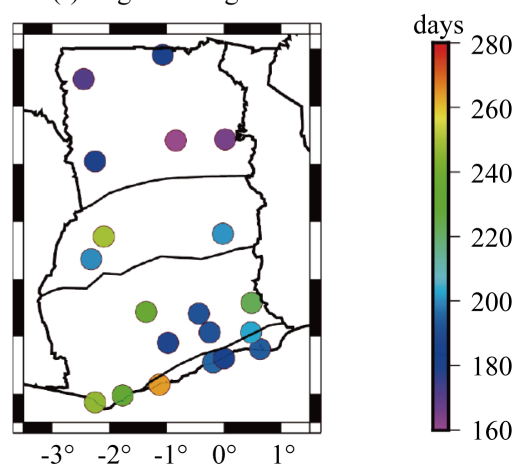

Figure 2. Onset and cessation dates with the duration of the rainy season for the four agro-ecological zones in Ghana.

Table 2 and Table 3 show the mean rainfall onset dates with the duration and cessation dates for each station from the gauge measurements and RegCM4 model respectively. Figure 2 also gives a graphical representation of the mean onset and cessation dates of the rainy season for all stations from both the gauge and model.

\subsection{Duration of Rainy Season}

As represented in Table 2 and Table 3, the maximum duration of rainy season from the gauge was found to be 250 days for Ho, followed by Wenchi with 242 days. The minimum duration in Ghana was found to be for Navrongo with 183 days. From the model, the maximum duration of the rainy season was recorded at Saltpond with 264 days, followed by Wenchi with 249 days. The minimum duration for the rainy season was recorded at Tamale with 160 days. On average, the forest and transition zones recorded the longest rainy season whereas the savannah and coastal zones recorded relatively shorter rainy seasons, with a total of less than 200 days. The 
Table 2. Distribution of mean rainfall onset and cessation dates from gauge.

\begin{tabular}{cccc}
\hline Station & GMet Mean OD & Duration (days) & GMet Mean CD \\
\hline Abetifi & $91 \pm 10$ & 226 & $317 \pm 07$ \\
Accra & $123 \pm 07$ & 187 & $313 \pm 05$ \\
Ada & $116 \pm 07$ & 194 & $310 \pm 05$ \\
Akatsi & $109 \pm 07$ & 184 & $293 \pm 07$ \\
Akim Oda & $74 \pm 07$ & 240 & $314 \pm 10$ \\
Axim & $87 \pm 10$ & 239 & $326 \pm 10$ \\
Bole & $100 \pm 05$ & 215 & $315 \pm 05$ \\
Ho & $70 \pm 07$ & 250 & $320 \pm 10$ \\
Kete Krachie & $121 \pm 07$ & 213 & $334 \pm 05$ \\
Koforidua & $94 \pm 05$ & 220 & $314 \pm 10$ \\
Kumasi & $80 \pm 05$ & 244 & $324 \pm 10$ \\
Navrongo & $132 \pm 05$ & 183 & $315 \pm 05$ \\
Saltpond & $112 \pm 07$ & 202 & $314 \pm 05$ \\
Sunyani & $83 \pm 05$ & 236 & $319 \pm 10$ \\
Takoradi & $104 \pm 10$ & 222 & $327 \pm 05$ \\
Tamale & $127 \pm 07$ & 185 & $312 \pm 05$ \\
Tema & $120 \pm 07$ & 187 & $308 \pm 05$ \\
Wa & $111 \pm 05$ & 194 & $306 \pm 05$ \\
Wenchi & $90 \pm 07$ & 242 & $332 \pm 07$ \\
Yendi & $92 \pm 05$ & 203 & $315 \pm 05$ \\
\hline
\end{tabular}

Table 3. Distribution of mean rainfall onset and cessation dates from RegCM4.

\begin{tabular}{|c|c|c|c|}
\hline Station & RegCM4 Mean OD & Duration (days) & RegCM4 Mean CD \\
\hline Abetifi & $93 \pm 10$ & 192 & $284 \pm 05$ \\
\hline Accra & $112 \pm 05$ & 196 & $308 \pm 05$ \\
\hline Ada & $110 \pm 05$ & 194 & $304 \pm 05$ \\
\hline Akatsi & $76 \pm 07$ & 203 & $279 \pm 05$ \\
\hline Akim Oda & $115 \pm 05$ & 188 & $303 \pm 05$ \\
\hline Axim & $85 \pm 05$ & 246 & $330 \pm 05$ \\
\hline Bole & $110 \pm 05$ & 179 & $289 \pm 05$ \\
\hline Но & $76 \pm 07$ & 223 & $299 \pm 07$ \\
\hline Kete Krachie & $105 \pm 10$ & 201 & $306 \pm 05$ \\
\hline Koforidua & $93 \pm 10$ & 192 & $285 \pm 05$ \\
\hline Kumasi & $114 \pm 07$ & 236 & $319 \pm 05$ \\
\hline Navrongo & $120 \pm 05$ & 181 & $301 \pm 05$ \\
\hline Saltpond & $61 \pm 05$ & 264 & $325 \pm 05$ \\
\hline Sunyani & $115 \pm 15$ & 200 & $315 \pm 05$ \\
\hline Takoradi & $86 \pm 05$ & 232 & $318 \pm 05$ \\
\hline Tamale & $128 \pm 07$ & 160 & $288 \pm 05$ \\
\hline Tema & $112 \pm 05$ & 186 & $298 \pm 05$ \\
\hline $\mathrm{Wa}$ & $130 \pm 07$ & 171 & $300 \pm 05$ \\
\hline Wenchi & $88 \pm 15$ & 249 & $306 \pm 05$ \\
\hline Yendi & $123 \pm 07$ & 165 & $288 \pm 05$ \\
\hline
\end{tabular}


mean rainfall within these zones are normally observed to be between $740 \mathrm{~mm}$ and $890 \mathrm{~mm}$, which supports very little rain-fed agriculture. Rainfall patterns for the forest and transition zones are bi-modal and rainfall values are typically higher than that of the coastal and savannah zone. However, the peak rainfall of the transition is mainly in September and that of the forest is in June. These zones tend to have a longer growing season and as such, form the productive zones of the country in terms of cash crop and food production [2].

\subsection{Validation}

The upper panels of Figure 3 show the bias between the gauge and model in determining the rainfall onset, cessation and duration of the rainy season respectively. There is quite a good agreement between the two datasets in determining the rainfall onsets, with bias of less than 30 days countrywide. However, a large disparity in onset determination is observed for Saltpond, with a bias of about 60 days. This is followed by that of Sunyani, Akatsi, Akim-Oda and Wenchi, with bias of about 40 - 50 days. Estimation of cessation dates from gauge rightly agrees with that of the model, over the entire country, with bias of less than 30 days. Hence, the bias in the duration of the rainy season is largely attributable to the disparities in onset estimation and not necessarily that of cessation. These are further corroborated by the RMSE values obtained for each station, as shown in the lower panel of Figure 3. A high RMSE is again seen for the onset determination at Saltpond, Wenchi, Akatsi, Sunyani and Akim-Oda: an indication of the disparity in onset determination between the gauge and model. RMSE between the gauge and model were less than 10 days over the other stations. RMSE for the cessation dates were also below 15 days. Furthermore, Pearson's correlation was performed to test the agreement between onset and cessation determination for both gauge and model. Correlation coefficients for both the rainfall onset and cessation
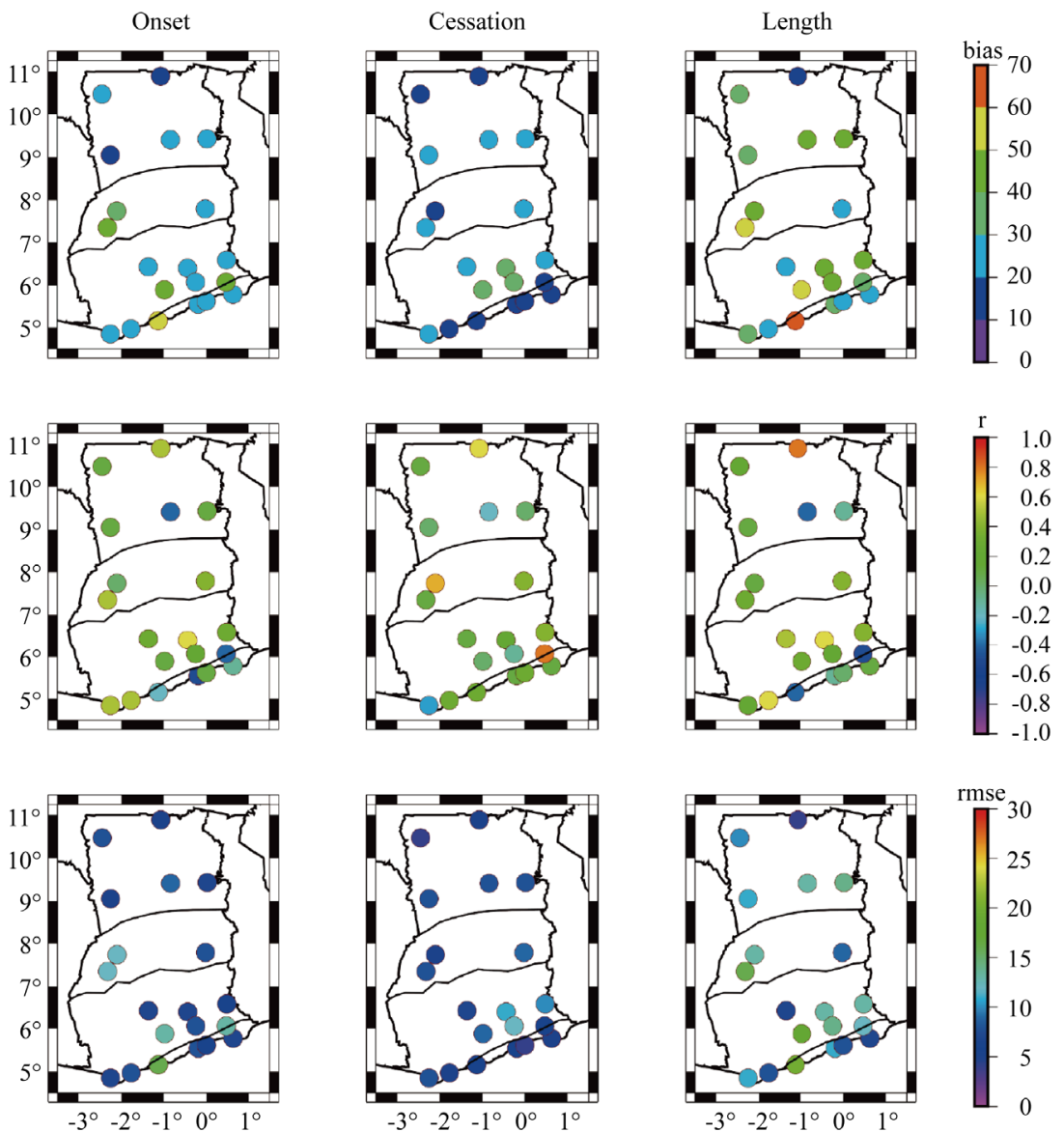

Figure 3. Bias (upper), Pearson's correlation co-efficient (middle) and root mean square error (lower) between GMet measured and RegCM4 simulated rainfall data for onset (left), cessation (middle), and the duration of the rainy season (right). 
Table 4. Distribution of mean rainfall onset and cessation dates for the various zones from gauge.

\begin{tabular}{cccc}
\hline Zone & GMet Mean OD & Duration (days) & GMet Mean CD \\
\hline Savannah & $117 \pm 05$ & 196 & $313 \pm 05$ \\
Transition & $98 \pm 07$ & 230 & $328 \pm 07$ \\
Forest & $86 \pm 07$ & 234 & $320 \pm 10$ \\
Coastal & $117 \pm 07$ & 191 & $307 \pm 05$ \\
\hline
\end{tabular}

Table 5. Distribution of mean rainfall onset and cessation dates for the various zones from RegCM4.

\begin{tabular}{cccc}
\hline Zone & GMet Mean OD & Duration (days) & GMet Mean CD \\
\hline Savannah & $122 \pm 05$ & 171 & $293 \pm 05$ \\
Transition & $103 \pm 10$ & 216 & $319 \pm 05$ \\
Forest & $90 \pm 07$ & 216 & $306 \pm 05$ \\
Coastal & $94 \pm 05$ & 209 & $302 \pm 05$ \\
\hline
\end{tabular}

dates typically ranged between 0.4 and 0.8 . Negative correlations were observed for Tamale and the entire coastal zone. These are likely attributable to the poor performance of the RegCM4 model in determining the rainfall onsets over the aforementioned locations. The correlation for the cessation was generally low over the country. However, Akuse, Wenchi and Navrongo showed higher correlations.

\section{Conclusions}

In this paper, we investigated the onset, cessation and duration of the rainy season using both simulated rainfall data from RegCM4 model and GMet gauge data, over Ghana from 1998 to 2012 using the fuzzy-logic approach. The mean onsets from both the gauge and model were found to be within the second dekad of March and first dekad of May countrywide. On the other hand, the mean cessation was identified from RegCM4 to be in the third dekad of October whereas the gauge found the third dekad of October to the second dekad of November as the mean cessation date. Furthermore, the average duration of the rainy season was found to be less than 200 days in the savannah and coastal zones whereas the transition and forest zones recorded more than 200 days (see Table 4 and Table 5). Finally, the validation of RegCM4-gauge onsets, cessation and duration of rainy season revealed a bias of less than 30 days and RMSE of less than 15 days over all stations but Saltpond. Pearson's correlation for both the rainfall onset and cessation typically ranged between 0.4 and 0.8 . Negative correlations were however recorded for Tamale in the savannah zone, and the entire coastal zone.

These findings support the forth and back migration of the ITD, which regulates the pressure system of West African Monsoon. In addition, topography and nature of land cover are major moderators of convective activities, and consequently, rainfall onsets and cessation. These factors were accounted for in RegCM4. Further study to assess the contributions of thermodynamic processes and other local effects is under consideration. These findings have very useful applications for water resource management, food security and other socio-economic activities in Ghana, considering their strong dependence on the dynamics of the rainfall season.

\section{Acknowledgements}

We thank the Abdus-Salam International Center for Theoretical Physics (ICTP) and Ghana Meteorological Agency (GMet) for provision of RegCM4 simulation and guage data respectively.

\section{References}

[1] Owusu, K. and Waylen, P. (2009) Trends in Spatio-Temporal Variability in Annual Rainfall in Ghana (1951-2000). Weather, 64, 115-120. http://dx.doi.org/10.1002/wea.255

[2] Amekudzi, L.K., Yamba, E., Preko, K., Asare, E.O., Aryee, J., Baidu, M. and Codjoe, N.A.S. (2015) Variabilities in 
Rainfall Onset, Cessation and Length of Rainy Season for the Various Agro-Ecological Zones of Ghana. Ecological Impacts of Climate Change, 3, 416-434. http://dx.doi.org/10.3390/cli3020416

[3] Manzanas, R., Amekudzi, L., Preko, K., Herrera, S. and Gutierrez, J. (2014) A Comparison of Methods to Determine the Onset of the Growing Season in Nigeria. Climatic Change, 124, 805-819. http://dx.doi.org/10.1007/s10584-014-1100-9

[4] Olaniran, O.J. (1983) The Onset of the Rains and the Start of the Growing Season in Nigeria. Nigerian Geographical Journal, 26, 81-88.

[5] Olaniran, O. (1984) The Start and End of the Growing Season in the Niger River Basin Development Authority Area of Nigeria. Malaysian Journal of Tropical Geography, 9, 49-58.

[6] Adejuwon, J., Balogun, E. and Adejuwon, S. (1990) On the Annual and Seasonal Patterns of Rainfall Uctuations in Sub-Saharan West Africa. International Journal of Climatology, 10, 839-848. http://dx.doi.org/10.1002/joc.3370100806

[7] Odekunle, T. (2006) Determining Rainy Season Onset and Retreat over Nigeria from Precipitation Amount and Number of Rainy Days. Theoretical and Applied Climatology, 83, 193-201. http://dx.doi.org/10.1007/s00704-005-0166-8

[8] Le Barbe, L., Lebel, T. and Tapsoba, D. (2002) Rainfall Variability in West Africa during the Years 1950-90. Int. J. Climate, 15, 187-202. http://dx.doi.org/10.1175/1520-0442(2002)015<0187:RVIWAD>2.0.CO;2

[9] Cocheme, J., et al. (1967) An Agroclimatology Survey of a Semiarid Area in Africa South of the Sahara. Technical Note No. 86.

[10] Benoit, P. (1977) The Start of the Growing Season in Northern Nigeria. Agricultural Meteorology, 18, 91-99. http://dx.doi.org/10.1016/0002-1571(77)90042-5

[11] Omotosho, J. (2002) Synoptic Meteorology: Pathway to Seasonal Rainfall Prediction for Sustainable Agriculture and Effective Water Resources Management in West Africa but Nigeria in Particular. Journal of the Nigerian Meteorological Society, 3, 81-89.

[12] Giorgi, F., Coppola, E., Solomon, F., Mariotti, L., Sylla, M., Bi, X., Elguindi, N., Diro, G., Nair, V., Giuliani, G., Turuncoglu, U., Cozzini, S., Guttler, I., Brien, T., Tawfik, A., Shalaby, A., Zakey, A., Steiner, A., Stordal, F., Sloan, L. and Brankovic, C. (2012) RegCM4: Model Description and Preliminary Tests over Multiple CORDEX Domains. Climate Research, 52, 7-29. http://dx.doi.org/10.3354/cr01018

[13] Browne, N. and Sylla, M. (2012) Regional Climate Model Sensitivity to Domain Size for the Simulation of the West African Summer Monsoon Rainfall. International Journal of Geophysics, 2012, 1-17. http://dx.doi.org/10.1155/2012/625831

[14] Sultan, B. and Janicot, S. (2000) Abrupt Shift of the ITCZ over West Africa and Intra-Seasonal Variability. Geophysical Research Letters, 27, 3353-3356. http://dx.doi.org/10.1029/1999GL011285

[15] Mounier, F., Janicot, S. and Kiladis, G.N. (2008) The West African Monsoon Dynamics Part III: The Quasi-Biweekly zonal Dipole. Journal of Climate, 21, 1911-1928. http://dx.doi.org/10.1175/2007JCLI1706.1

[16] Qian, J.H. (2008) Why Precipitation Is Mostly Concentrated over Islands in the Maritime Continent. Journal of the Atmospheric Sciences, 65, 14281441. http://dx.doi.org/10.1175/2007JAS2422.1

[17] Qian, J.H., Robertson, A.W. and Moron, V. (2010) Interactions among ENSO, the Monsoons, and Diurnal Cycle in Rainfall Variability over Java, Indonesia. J Atmos Sci, 67, 35093524. http://dx.doi.org/10.1175/2010JAS3348.1

[18] Dodd, D. and Jolliffe, I. (2001) Early Detection of the Start of the Wet Season in Semiarid Tropical Climates of Western Africa. International Journal of Climatology, 21, 1251-1262. http://dx.doi.org/10.1002/joc.640

[19] Amekudzi, L.K., Bracher, A., Bramstedt, K., Rozanov, A., Bovensmann, H. and Burrows, J.P. (2008) Towards Validation of SCHIAMACHY Lunar Occultation $\mathrm{NO}_{2}$ Vertical Profiles. Advances in Space Research, 41, 1921-1932. http://dx.doi.org/10.1016/j.asr.2007.06.055

[20] Quansah, E., Amekudzi, L.K., Preko, K., Aryee, J., Boakye, R.O., Boli, D. and Salifu, M.R. (2014) Empirical models for Estimating Global Solar Radiation over the Ashanti Region of Ghana. Journal of Solar Energy, 2014, 1-6. 